\title{
The Development and Application of Co-design Modules for Multidisciplinary Collaboration and Facilitating Creativity: An Experience from D-School@NTU
}

\author{
Shih-Yao Lai, Liang-Gui Yu, Shang-Hsien Hsieh, Mei-Mei Song, and Te-Sheng Chang
}

\begin{abstract}
Convergent and divergent thinking are both important for solving problems. The former helps to produce a known answer; while the latter to bring the forth ones. Base on the results of a previous research (2014-16) called "i.edu", we found multidisciplinary collaboration was beneficial to students' project-based and problem-solving learning. However, the process could be more effective if proper collaborative methods were utilized. In this research, we adopted the concept of "collaborative design" to develop method-modules for multidisciplinary groups to work effectively with multiple perspectives and thinking to hence better creativity. For testing the modules and inspiring new possible ones, we designed a workshop in D-School@NTU, in which 24 under- and postgraduate students from different disciplines teamed up to learn the module use and design. A neighborhood of Taipei city, Nanjichang, were selected for the learning-based project. Participants' groups needed to develop action plans, on which their collaborative working method-modules could be based and proposed. From the participants' feedbacks, the observation of the design process, and the design results, the given modules relatively helped the production of action plans. All groups could propose method-modules that reveal various levels of creativity, although most of them are still inapplicable. The task of the workshop also derives a question-Is working method a good object for design?
\end{abstract}

Index Terms-Collaborative design, creativity, intelligent problem solving, participatory design.

\section{INTRODUCTION}

In a time of a rapidly changing society with fast technology development, engineering problems become more and more complicated. In the past twenty years, many researches on engineering education stress the inefficiency of conventional curriculum. Sternberg and Lubart point out that students of contemporary engineering fields are short of experiences of teamwork and skills of communication, short-sighted about their disciplines, and insufficient to design capability and

Manuscript received July 20, 2018; revised August 21, 2018. This work was supported in part by the Taiwan Ministry of Science and Technology under MOST 105-2511-S-002-016-MY3.

Shih-Yao Lai and Liang-Gui Yu are with the Graduate Institute of Building and Planning, National Taiwan University, Taipei city, 10617 Taiwan (e-mail: laisy@ntu.edu.tw, d04544003@ntu.edu.tw).

Shang-Hsien Hsieh is with the Department of Civil Engineering, National Taiwan University, Taipei city, 10617 Taiwan (e-mail: shhsieh@ntu.edu.tw).

Mei-Mei Song is with the Graduate Institute of Futures Studies, Tamkang University, New Taipei city, 25137 Taiwan (e-mail: song@ @ail.tku.edu.tw).

Te-Sheng Chang is with the Department of Education and Human Potentials Development, National Dong Hwa University, Hualien County, 97401 Taiwan (e-mail: achang@ gms.ndhu.edu.tw). creativity [1]. Prados states that engineering education emphasizes the teaching and training of skills and techniques, but fails to foster engineering students the ability to catch up with the progress of modern technology and the pace of innovation [2]. Rugarcia, Felder, Woods, and Stice also address that in order to deal with the society of rapid change, development of diverse knowledge and the merging social responsibilities, the engineering education must include the knowledge cultivation and capabilities' training, such as those of independent learning, problem-solving, critical thinking, creativity, team collaboration, integration, and comprehensive thinking, as well as the positive attitude and ability to integrating knowledge [3]. Recent studies also argue that the modern engineering education, opposite to the nurture of creativity, emphasizes the standardization and examination, which stresses the quantity rather than the quality of the research students. What is demanded today is creative experts. The purpose of education is to identify and develop existing creativity and potential innovation of each individual [4]. The conventional engineering education that delivers professional techniques and knowledge can no longer meet the contemporary engineering students' needs of fostering creative potentiality and flexible thinking [5]. Being short of creativity, engineering students, while facing problems, tend to constrain themselves with existing method when handling the difficulty. The innovative technology then can hardly be developed to solve the problem that the society encounters at present and in the future [6]. Through these arguments, creativity can be clearly identified as one of the most important capabilities that engineering education should promote.

The modern research of creativity started from American psychologist Joy Paul Guilford, who first time defined the nature of creativity as the theme of his research in 1950 [7]. He then claimed in 1967 that in the problem-solving process there are two type of thinking, the convergent and divergent ones. The convergent thinking helps to derive the single "best" answer to a clearly defined problem; while the divergent thinking, in contrary, helps to draw on ideas from multiple disciplines to reach a deeper understanding of the problem, and could bring profound answers to the problem. In comparison of these two approaches to problem-solving, convergent thinking emphasizes speed, accuracy, and logic, while divergent one fluency, flexibility, originality, and elaboration [8]. In VanGundy and Naiman's previous study about creativity and collaboration in 2003, they indicated, "If you have ideas but don't act on them, you are imaginative but not creative" [9]. Those are emphasized in convergent and 
divergent thinking could be related to the production of ideas (fluency, flexibility, originality, and elaboration) and practical action (speed, accuracy, and logic), and both thinking types are important for creativity. Therefore, to cultivate the creativity of students, it is an important task in engineering education to give students abilities of both types of problem-solving approaches.

\section{PREVIOUS EXPERIENCES IN ENGINEERING EDUCATION}

In the realm of engineering, Bratteteig and Wagner review the experiences and conclusion of related research, and point out that the creative design is a social process based on individuals' interactions and collaborations, which includes four premises and elements-the support, openness, multiplicity of perspectives, mobilizing resources, and space for design ideas [10]. Group collaboration and multidisciplinary thinking, therefore, can also be an essential foundation to elevate creativity in the design process.

This project was inspired by a finding combining the observation, outcomes, and students' feedbacks of a prior research project, "Development of Interdisciplinary Engineering Curriculum for Innovative Design (i.edu)" (2014-16), which aimed at the issue of, in order for innovative solution, how multidisciplinary collaboration could be effectively operated and creativity fostered while facing complicated and changeable problems. The curriculum was designed by grouping three courses from Department of Civil Engineering, Graduate Institute of Building and Planning, and Department of Mechanical Engineering at National Taiwan University (NTU). The courseware, therefore, were designed and developed jointly by instructors from fields of Civil Engineering, Architecture, Mechanical Engineering, and Futures Studies. In the second and the third years the research team set up the course based on a real neighborhood, real people, and their real problems, for which students of different backgrounds worked together and produced an environment improvement proposal.

Students, divided into three groups, needed to investigate the neighborhood, define the problems and issues, and then propose a strategy and related action plan for the community's future. The reflection from the teachers and the feedback from the students on teaching and learning were collected and analyzed to serve as a reference for curriculum development. In this project-based course and (real) problem-based learning process, one of the research findings was that a working method (or scaffolding/platform) is useful for beginners of this community design approach course project working effectively.

In the second year of this community-planning mode of project-based course, all the student groups encountered, more or less, difficulties of knowing how and what to do correctly in order to "meet the requirements of the planning discipline." The engineering students tended to ask "what is community planning and design" and forgot the purpose of cross-disciplinary collaboration is to bring in multiple perspectives and ways of thinking, even though the significance of this concept has been delivered several times. The strong recognition and presumption of disciplinary boundaries hindered students from thinking and making observation with their own backgrounds and perspectives as contribution, but formed another layer of difficulty in their teamwork. Among them one group also showed that a method as scaffolding tool could help the beginners of planning-like project work better together and overcome the difficulty in a certain degree. The group used to have serious problems of site investigation, yet finally struggled for a survival way out. The working method made the group members could just go to the site, observe and find some designated activities and physical elements on site.

Based on the experiences, a new integrated research project named "Transdisciplinary Engineering Education for Creativity" was initiated, following the theme of multidisciplinary collaboration and creativity to produce an experimental curriculum. All subprojects collaborate together to developed modules that, as the essences of the curriculum, will be applied and evaluated through a series of workshops courses in the D-School@NTU as experiments. The outcome should include a set of teaching and working modules based on the collaborative design (CD) / participatory design (PD) that can help engineering students to enhance their multidisciplinary collaboration and creative thinking, and a series of modules promotions. The aim of developing the teaching and practicing modules was inspired by the idea of applying working methods for effective collaboration.

\section{EDUCATION MODULE OF CD}

Compare with the problem-solving-based courses designed in i.edu, in this research, we needed to develop a new framework of course focusing on the methodology of CD. Therefore, to find a proper education module of $\mathrm{PD} / \mathrm{CD}$, we studied several researches of $\mathrm{CD}$ education, and consulted the experiences of "Informatik" and "Digital Media" courses at Bremen University since 2000, which established a teaching module of PD [11].

In the first stage of their courses, the tutors introduced the concept, methods and applications of PD through lectures to give students the epistemological basis. In the next stage, each group of students was led by an "expert student" who had been trained in advance to demonstrate those methods, and the tutors would give assistance and advice if necessary. Finally, all the students gathered and discussed the experiences during the demonstration (Table I).

In our research, we tried to develop an education module of $\mathrm{CD}$ based on the experience at Bremen University and executed a two-day workshop in D-School@NTU on September $5^{\text {th }}$ and $6^{\text {th }}, 2017$ to test this module (Fig. 1).

TABLE I: The COURSE SChEDULE OF "INFORMATIK" AND "DigitAl MEDIA" COURSES AT BREMEN UNIVERSITY [11]

\begin{tabular}{ll}
\hline \hline Week & Course Contents \\
\hline $1-3$ & Introduction to PD \\
$4-6$ & Method: Ethnography \& Contextual Design \\
7 & Method: Metaphors Game \\
8 & Method: CARD Game \\
9 & Method: Personas \\
10 & Method: Scenario Based Design \\
$11-12$ & Paper Prototyping \& Usability Tests \\
13 & Comparison \& General Discussion \\
\hline \hline
\end{tabular}




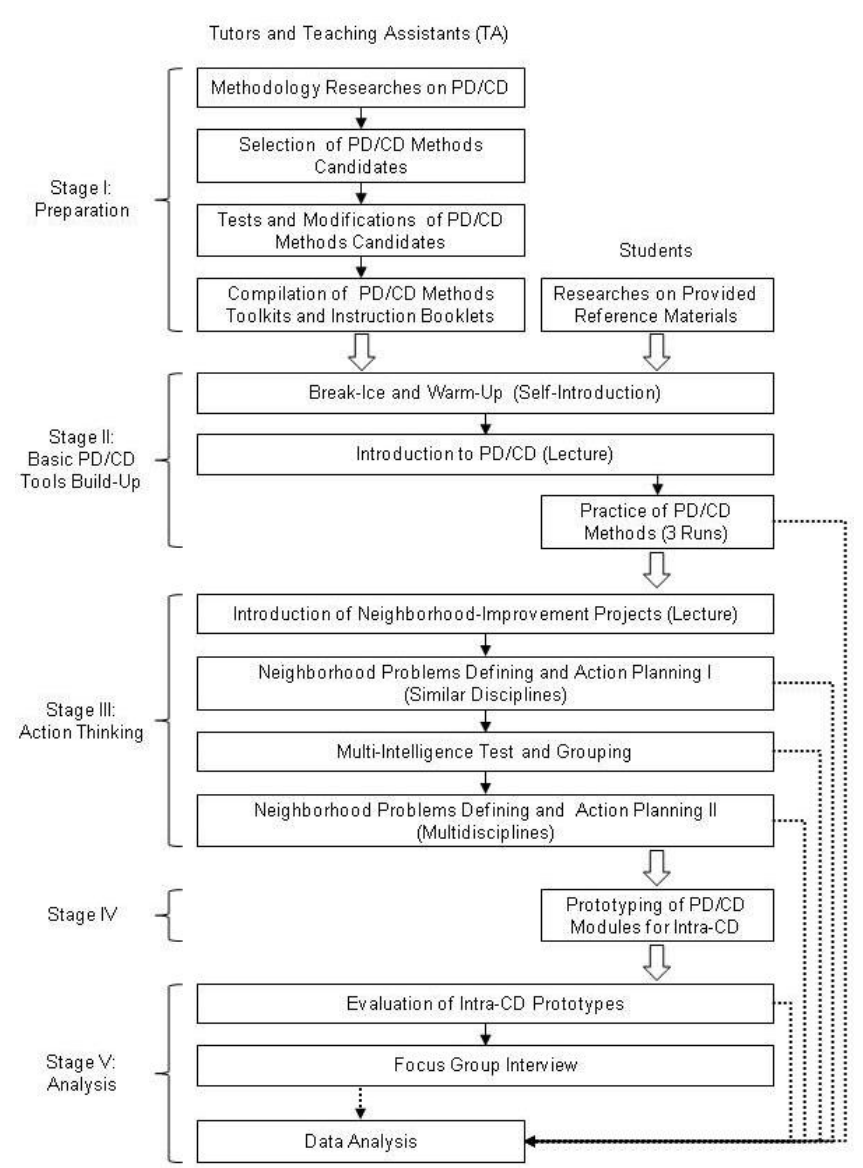

Fig. 1. The curriculum flow chart of PD/CD workshop in D-School@NTU.

\section{EXPERIMENTAL DESIGN}

\section{A. CD Workshop}

For planning and preparing the workshop, the research team reviewed several researches on methodologies of PD and $\mathrm{CD}$, and selected a few possible adopting models, which were tested and modified by the group members as shown in Fig. 2, and then compiled as toolkits with instruction booklets and operational devices (Fig. 3) for attending students.

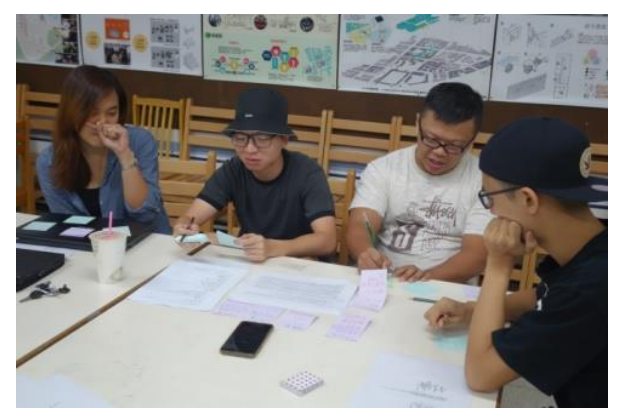

Fig. 2. The research team developed and tested the PD/CD toolkits.

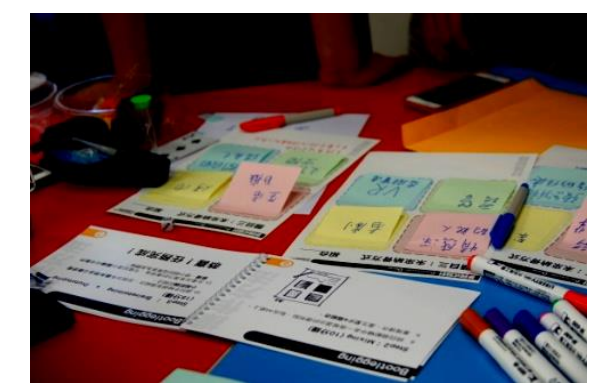

Fig. 3. PD/CD toolkits demonstrated in the workshop.
The research team produced toolkits of various CD methods, including Open Space, Bootlegging, Empathy Game, Consensus First, Exquisite Corpse, and Collaborative Situation Construction. Compared with the Bremen University's cases mentioned above [11], students in this workshop were not led by "expert student" to demonstrate those methods; rather, they would be expected to learn from the toolkits packages and drive their design of working methods. That is, the toolkits were regarded as the primary working methods for the learning of CD. Students might understand the fundamental methods through the toolkits, by following the booklets' instruction and practicing the methods by themselves (Fig. 4). Tutors and teaching assistants would just observe how they carried on and gave advices if necessary.

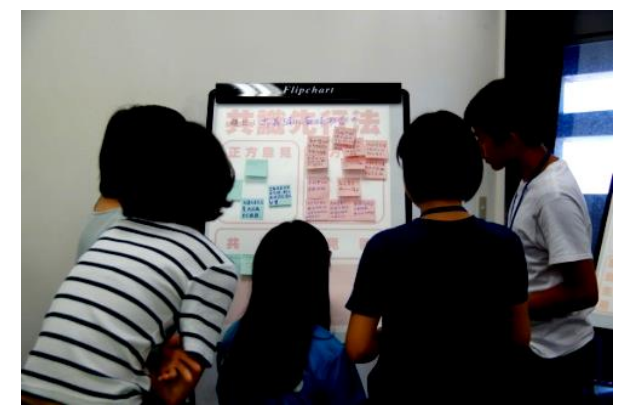

Fig. 4. Students practiced PD/CD methods prepared as the toolkits.

To find out if the disciplinary backgrounds and characteristics compositions of students affect the creativity of prototyping design, the team introduced a multi-intelligence test that proposed by Dr. Howard Gardner in 1983 [12] (Fig. 5), which helped students to recognize their intelligent characteristics as one reference for their (similar or diverse) grouping arrangement. This was then followed by stages of grouping based on two methods (in similar and different disciplinary in this workshop. We assumed that students from the similar major(s) or disciplinary backgrounds would show "convergent" thinking due to the similar knowledge, skill development, and interrelated mindset, while the others would show "divergent" thinking due to the differences in their knowledge, skill, and so forth. To verify this hypothesis, we also arranged two-stage missions for students, in similar vs. different composition of disciplinary background, to discover the problems of the selected neighborhood of Taipei city, Nanjichang, with the provided reference materials and for developing their action plans.

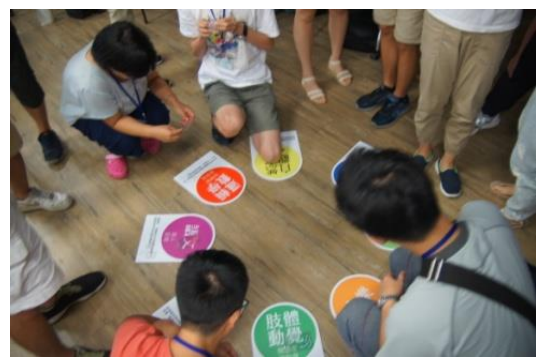

Fig. 5. With the help of multi-intelligence test, students recognized their intelligent characteristics.

After the development of two stages of action planning, students must propose intra-collaborative working 
methods-modules that aim at the Nanjichang neighborhood and meet the action plan's task. Those modules would be evaluated under the guidelines of creativity [8].

\section{B. Data Collection and Analysis}

In this research, both qualitative and quantitative methods were used to analyze the effectiveness of teaching and learning as well as the conditions of multidisciplinary collaboration and the creativity fostering. Through the entire process of the workshop, one teaching assistant was assigned to observe and record the discussion of each group. For each activity, students were asked to do questionnaires under anonymous circumstance to evaluate the effectiveness (level 1 to 10,1 for "strongly disagree" and 10 for "strongly agree") of each operation. The final products as prototypes of CD method-modules for enhancing intra-collaboration were also evaluated by the tutors and the teaching assistants. After the workshop, every student participated a semi-structured focus group interview, and the products of each process were photographed as data for further analysis.

\section{RESUlTS AND DISCUSSION}

\section{A. Students Composition}

There were 24 students attending this workshop (Table II). In gender ratio, there were 15 male $(62.5 \%)$ and 9 female $(37.5 \%)$ students. In grades ratio, there were 7 freshman (29.2\%), 8 sophomores (33.3\%), 6 juniors (25\%), 2 seniors $(8.3 \%)$, and 1 graduate student (4.2\%). In discipline ratio, we categorized the students on the basis of the classification method suggested by the College Entrance Examination Center of Taiwan since 1996, with which 2 were from information field (also from management) (8.3\%), 5 from engineering field (20.8\%), 2 from medicine and health field (8.3\%), 1 from geoscience and environment field (4.2\%), 2 from sociology and psychology field (8.3\%), 2 from mass communication field $(8.3 \%), 1$ from literature, history and philosophy field $(4.2 \%), 2$ from management field $(8.3 \%)$, and 7 from finance field $(29.2 \%)$.

In multi-intelligences analysis, male students showed preferences mainly on interpersonal (46.7\%), logical-mathematical (46.7\%), visual-spatial (40\%), intrapersonal $(40 \%)$ and bodily-kinesthetic $(26.7 \%)$, while female students mainly on intrapersonal (77.8\%), logical-mathematical (33.3\%) and visual-spatial (33.3\%). Furthermore, all students from the information and engineering fields showed preferences on logical-mathematical, all students from medicine-health field and sociology-psychology fields on intrapersonal (it was worth noting that students from medicine-health field chose this intelligence only), all students from mass communication field on visual-spatial, while no students from engineering field on visual-spatial.

TABLE II: PROFILES OF STUDENTS

\begin{tabular}{lllll}
\hline \hline ID & Gender & Grade & Discipline & Multi-intelligence \\
\hline 2032702 & Female & Freshman & Information & Musical-Rhythmic \\
& & & Management & $\begin{array}{l}\text { Logical- } \\
\text { Mathematical }\end{array}$
\end{tabular}

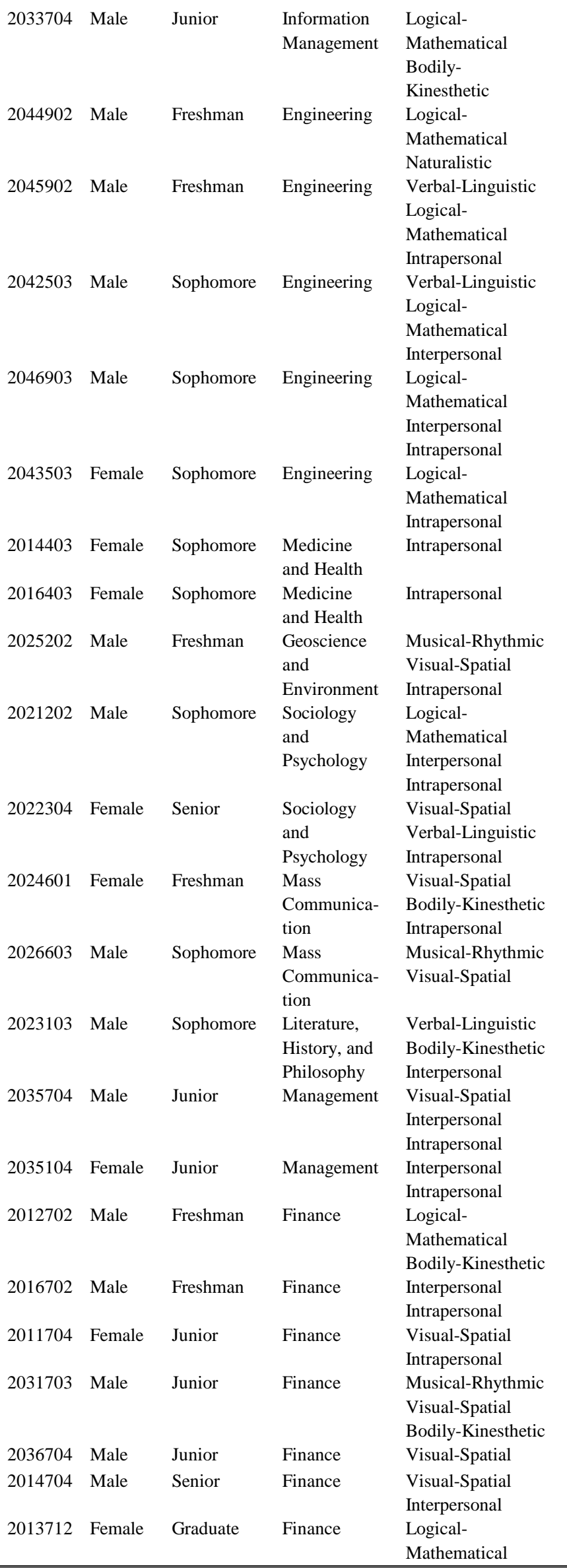

\section{B. Preference of Group Types and CD Methods}

After practicing three of the six toolkits, students were asked to evaluate these toolkits with 5 indices through 
questionnaires - 'easiness of operation', 'enhancement of group communication', 'consideration of diversity', 'stimulation of creativity', and 'formation of consensus.' According to the 19 valid responses, all attending students had teamwork experiences and preferred team made of multidisciplinary members. Most students agreed that the 6 toolkits were easy to employ (from 7.33 to 9.55 , Fig. 6). From the participatory observation of the toolkits demonstration by the teaching assistants, in general, students could operate the toolkits correctly with the help of booklets' instruction. These results preliminarily supported that the self-operating $\mathrm{CD}$ learning modules are workable.

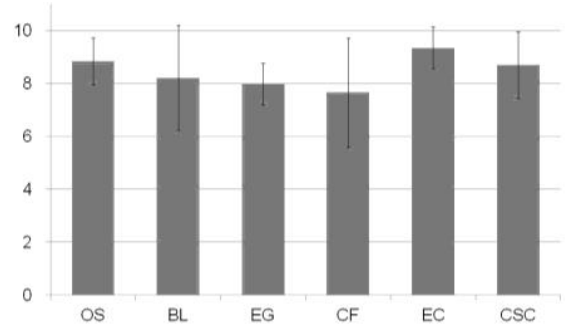

Fig. 6. Students' evaluation of "easiness of operation" about the 6 PD/CD toolkits. OS: open space, BL: bootlegging, EG: empathy game, $\mathrm{CF}$ : consensus first, EC: exquisite corpse, and CSC: collaborative situation construction.

When asked about the preferences of the 6 toolkits (Fig. 7), almost every student considered the graphic-oriented method (Exquisite Corpse) less helpful in enhancing the communication among group members, while practical-agenda-setting-oriented methods (Open Space, Consensus First, and Collaborative Situation Construction) seemed more helpful. Mixed-combination-oriented method (Bootlegging) seemed more efficient in stimulating the creativity of students, and role-playing-oriented method (Empathy Game) seemed helpful in expanding the thinking of students. These results suggest that a method with a certain constraint or frameworks could be more helpful than that with no or little constraint for students to expand their visions and thinking, and further led to stimulation of creativity.

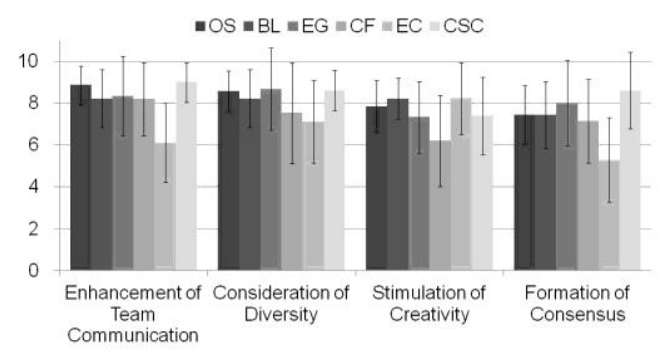

Fig. 7. Students' preferences for the $6 \mathrm{PD} / \mathrm{CD}$ toolkits.

It was worth noting that there is no correlation between the differences in disciplines and the obvious preferences to the methods. In the view of gender, however, male students agreed with the operational easiness of simple-group-discussion-oriented method (like Open Space), (Fig. 8) and effective consensus formation of mixed-combination-oriented method (like Bootlegging) (Fig. 9), while female students agreed more on the stimulation of creativity and consensus achievement the role-playing-oriented method (Empathy Game) could achieve
(Fig. 10). Interestingly, the latter result shows a contradiction with the multi-intelligence analysis as mentioned above. These results might reveal the importance of gender issue in the preference of thinking type.

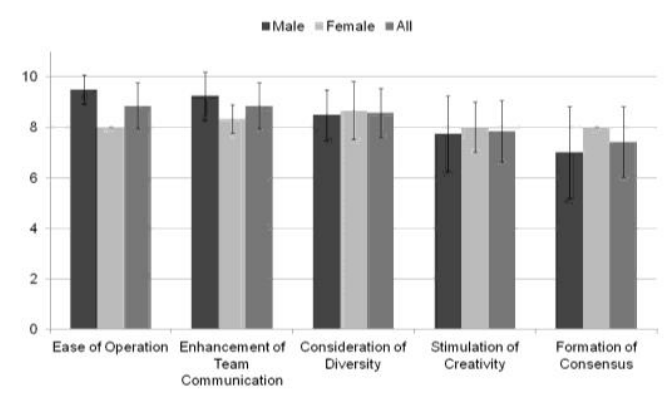

Fig. 8. Students' evaluation of open space method by different genders.

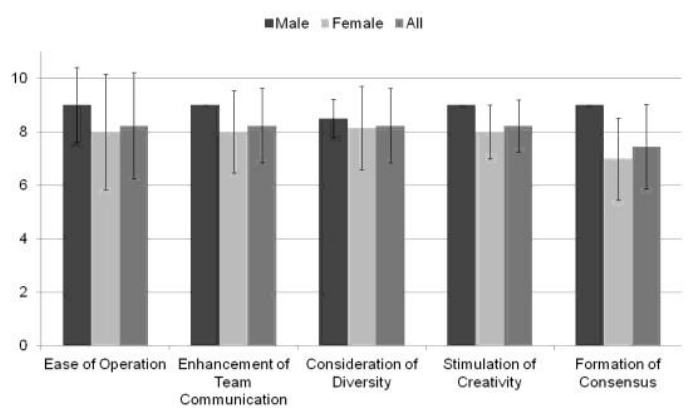

Fig. 9. Students' evaluation of bootlegging method in different genders

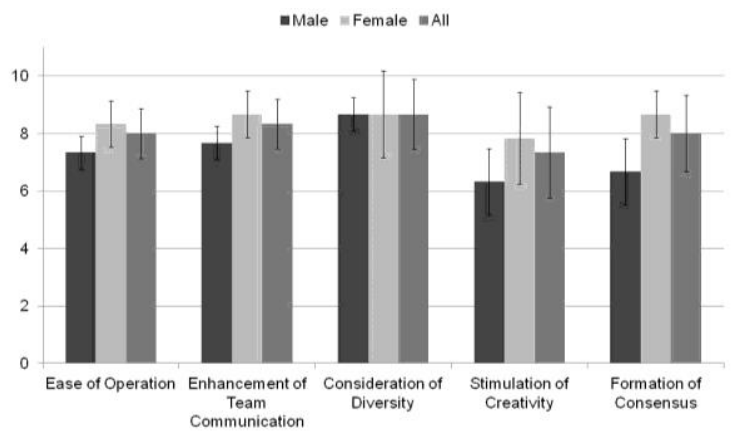

Fig. 10. Students' evaluation of empathy game method in different genders

\section{Problems Defining and Action Planning}

In the stage of problem defining and action plan proposing, the team examined the effectiveness of multidisciplinary collaboration by applying different grouping methods. Students were first divided into 6 groups according to their disciplines and then re-mixed into 5 groups based on the principle of creating maximum diversity with the different disciplines and multi-intelligence. The results came out of each mission of different grouping are shown in Table III and Table IV.

TABLE III: DEFINING PROBLEMS UNDER SIMILAR DISCIPLINARY GROUPING

\begin{tabular}{llll}
\hline \hline Group & ID & Discipline & Main Issues \\
\hline 1 & 2025202 & Geoscience and & $\bullet$ Aging and caring \\
& & Environment & $\bullet$ Elementary school revocation \\
2022304 & $\begin{array}{l}\text { Sociology and } \\
\text { Psychology }\end{array}$ \\
& & \\
2024601 & Mass \\
& Communication \\
& \\
& & \\
& Mass \\
& Communication
\end{tabular}




\begin{tabular}{|c|c|c|c|}
\hline \multirow[t]{4}{*}{2} & 2014403 & $\begin{array}{l}\text { Medicine and } \\
\text { Health }\end{array}$ & \multirow[t]{4}{*}{$\begin{array}{l}\text { - Housing preservation } \\
\text { - Night market and tourism }\end{array}$} \\
\hline & 2016403 & $\begin{array}{l}\text { Medicine and } \\
\text { Health }\end{array}$ & \\
\hline & 2021202 & $\begin{array}{l}\text { Sociology and } \\
\text { Psychology }\end{array}$ & \\
\hline & 2023103 & $\begin{array}{l}\text { Literature, } \\
\text { History, and } \\
\text { Philosophy }\end{array}$ & \\
\hline \multirow[t]{4}{*}{3} & 2035704 & Management & \multirow{4}{*}{$\begin{array}{l}\text { - Neighborhood politics } \\
\text { - Caring and space sharing }\end{array}$} \\
\hline & 2016702 & Finance & \\
\hline & 2011704 & Finance & \\
\hline & 2014704 & Finance & \\
\hline \multirow[t]{3}{*}{4} & 2032702 & $\begin{array}{l}\text { Information } \\
\text { Management }\end{array}$ & \multirow[t]{3}{*}{$\begin{array}{l}\text { - Neighborhood politics } \\
\text { - Community activities }\end{array}$} \\
\hline & 2033704 & $\begin{array}{l}\text { Information } \\
\text { Management }\end{array}$ & \\
\hline & 2035104 & Management & \\
\hline \multirow[t]{4}{*}{5} & 2012702 & Finance & \multirow{4}{*}{$\begin{array}{l}\text { - Ruined appearance } \\
\text { - Aging } \\
\text { - Night market }\end{array}$} \\
\hline & 2031703 & Finance & \\
\hline & 2036704 & Finance & \\
\hline & 2013712 & Finance & \\
\hline \multirow[t]{5}{*}{6} & 2044902 & Engineering & \multirow{5}{*}{$\begin{array}{l}\text { - Co-living of young people and } \\
\text { seniors }\end{array}$} \\
\hline & 2045902 & Engineering & \\
\hline & 2042503 & Engineering & \\
\hline & 2046903 & Engineering & \\
\hline & 2043503 & Engineering & \\
\hline
\end{tabular}

A notable circumstance was that by viewing the outcomes of the action plans and issues from the stage of similar disciplinary grouping for the first action plan, the group consisted of students from medical and humanity backgrounds (Group 2) did not focus more on the problems' human and institutional aspects as presumed, but their explicit and physical ones (Fig. 11). Rather, groups of the engineering background (Group 6) raise more humanitarian issues, such as co-habitation of elderly and younger people (Fig. 12).

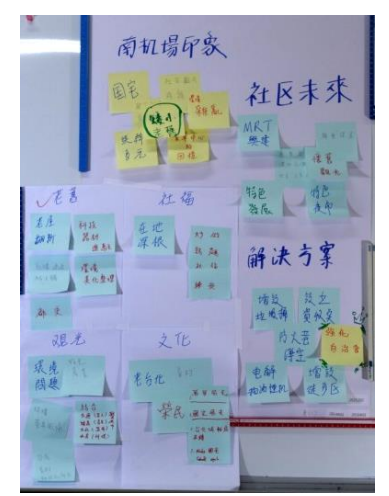

Fig. 11. Defining problems and action planning of Group 2.

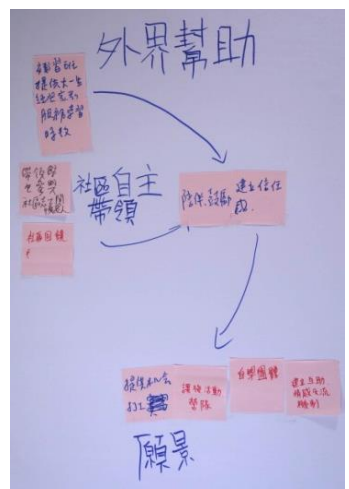

Fig. 12. Problems discovery and action plans of Group 6.
TABLE IV: DEFINING PROBLEMS UNDER MULTIDISCIPLINARY GROUPING

\begin{tabular}{|c|c|c|c|}
\hline Group & ID & Discipline & Main Issues \\
\hline \multirow[t]{4}{*}{ I } & 2032702 & $\begin{array}{l}\text { Information } \\
\text { Management }\end{array}$ & \multirow{4}{*}{$\begin{array}{l}\text { - Environment quality } \\
\text { - Solitary seniors interactions } \\
\text { - Preservation of living } \\
\text { memories }\end{array}$} \\
\hline & 2043503 & Engineering & \\
\hline & 2016403 & $\begin{array}{l}\text { Medicine and } \\
\text { Health }\end{array}$ & \\
\hline & 2036704 & Finance & \\
\hline \multirow[t]{6}{*}{ II } & 2042503 & Engineering & \multirow[t]{6}{*}{ - New immigrants family } \\
\hline & 2025202 & $\begin{array}{l}\text { Geoscience and } \\
\text { Environment }\end{array}$ & \\
\hline & 2022304 & $\begin{array}{l}\text { Sociology and } \\
\text { Psychology }\end{array}$ & \\
\hline & 2035704 & Management & \\
\hline & 2035104 & Management & \\
\hline & 2031703 & Finance & \\
\hline \multirow[t]{4}{*}{ III } & 2033704 & $\begin{array}{l}\text { Information } \\
\text { Management }\end{array}$ & \multirow{4}{*}{$\begin{array}{l}\text { - Ruined environment and } \\
\text { negative images } \\
\text { - Aging and vulnerable } \\
\text { - Insufficient neighborhood } \\
\text { cohesion }\end{array}$} \\
\hline & 2021202 & Sociology and & \\
\hline & 2012702 & Finance & \\
\hline & 2011704 & Finance & \\
\hline \multirow[t]{5}{*}{ IV } & 2044902 & Engineering & \multirow[t]{5}{*}{ - Aging, caring and education } \\
\hline & 2014403 & $\begin{array}{l}\text { Medicine and } \\
\text { Health }\end{array}$ & \\
\hline & 2024601 & $\begin{array}{l}\text { Mass } \\
\text { Communication }\end{array}$ & \\
\hline & 2016702 & Finance & \\
\hline & 2013712 & Finance & \\
\hline \multirow[t]{5}{*}{$\mathrm{V}$} & 2045902 & Engineering & \multirow[t]{5}{*}{ - Insufficient attention } \\
\hline & 2046903 & Engineering & \\
\hline & 2026603 & $\begin{array}{l}\text { Mass } \\
\text { Communication }\end{array}$ & \\
\hline & 2023103 & $\begin{array}{l}\text { Literature, } \\
\text { History, and } \\
\text { Philosophy }\end{array}$ & \\
\hline & 2014704 & Finance & \\
\hline
\end{tabular}

When students moved to the next stage to work with group members of diverse backgrounds, no completely new issue was raised except one about the issue of "new immigrants" (from cross-national marriages) in Group II (Fig. 13). It could be an outcome from the new perspective based on the different viewpoints of multidisciplinary members.

The following findings about the effectiveness of problem-solving between the similar and multidisciplinary grouping were derived from the 19 valid responses and in-depth interviews with the students.

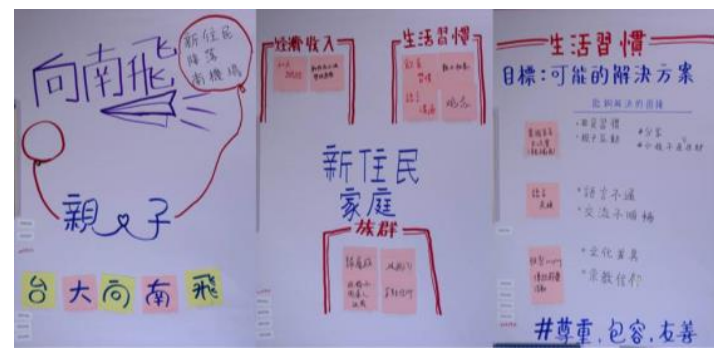

Fig. 13. Defining problems and action planning of Group II.

On the issue of effective communication within the group (intra-group), based on the quantitative result, students did not think the multidisciplinary grouping was effective for intra-group communication (Fig. 14). From the interview results, the students regarded the major problem of the 
multidisciplinary grouping was the difficulties of group communication and the consensus building.

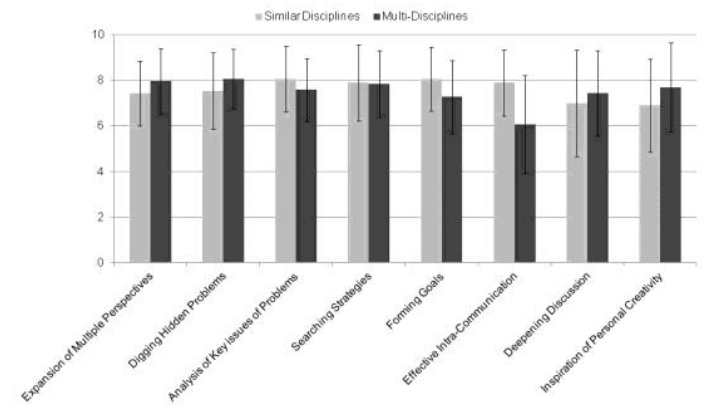

Fig. 14. Evaluation of effectiveness between similar and multidisciplinary grouping.

If taking the gender factor into account, male students thought more negatively about the effectiveness of multidisciplinary grouping in enhancing intra-communication than female ones (Fig. 15). Female students, compared to male ones, showed the better capability of empathizing differences and adapting themselves to the multidisciplinary grouping, if we take the analytic results into consideration that female students tend to favor the Empathy Game among the CD methods. In terms of the factor of different disciplines, the engineering students, as well as the sociology and psychology ones, all thought negatively that the multidisciplinary grouping was hard to improve the intra-group communication.

On the divergent thinking issues such as expanding multiple perspectives, seeing the hidden problems, and deepening discussion, based on the quantitative analysis, the students in general did not recognize that the multidisciplinary grouping was very helpful (Fig. 14). In their personal feedback, however, many students pointed out that multidisciplinary could make the group think and discuss with multiple dimensions, owing to the new knowledge shared by members of different disciplines and viewpoints and concerns from different fields. Yet so far the research team has no solid explanation to the incoherence between quantitative and qualitative results. It needs a further investigation.

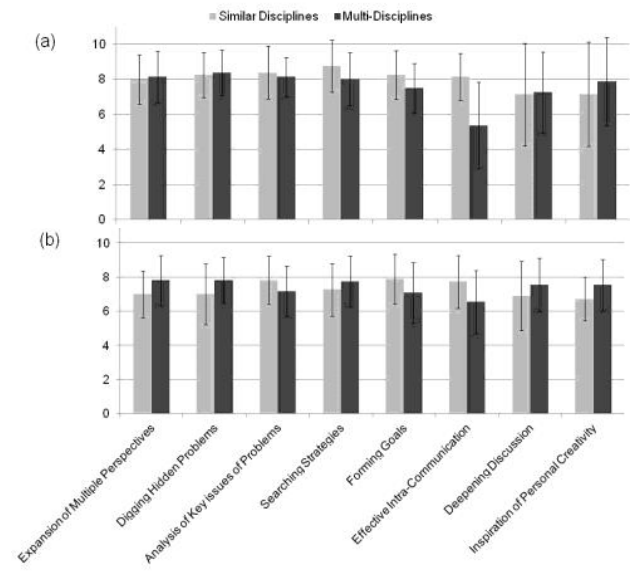

Fig. 15. Evaluation of effectiveness between similar and multidisciplinary grouping of different genders. (a) male, (b) female.

On the comparison of individual factors, gender did not affect intra-group communications, and similar as the disciplinary diversity, the engineering students did not regard the multidisciplinary grouping more helpful in expanding multiple perspectives than similar disciplinary grouping (Fig. 16). Nevertheless, the sociology and psychology students confirmed the contribution of the multidisciplinary grouping for the expanding multiperspectives and digging hidden problems (Fig. 16).

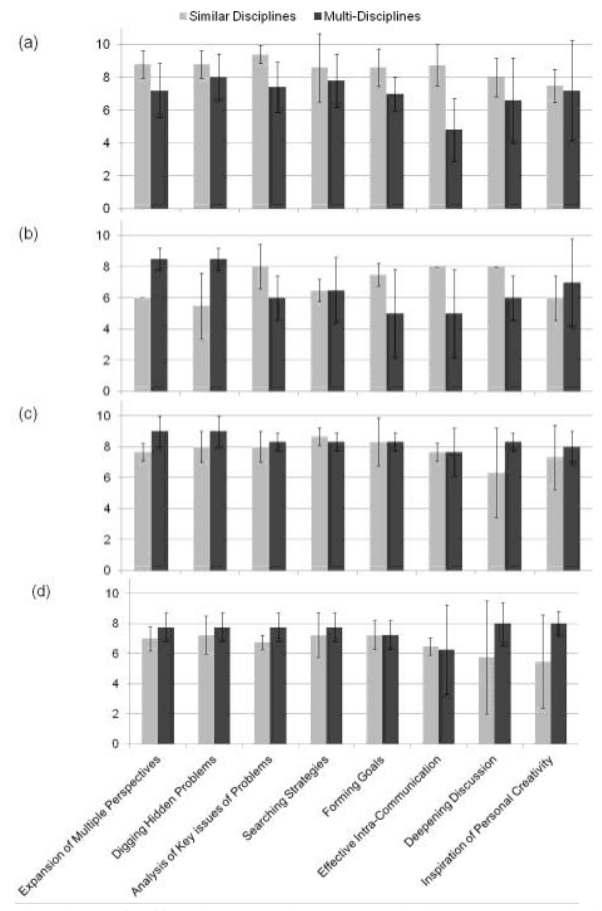

Fig. 16. Evaluation of effectiveness between similar and multidisciplinary grouping of different disciplines. (a) engineering, (b) sociology and psychology, (c) management, (d) finance.

On supporting deepening of group discussion, the sociology and psychology students found multidisciplinary grouping affected negatively (Fig. 16), while the finance and management students found it positive (Fig. 16).

On the convergent thinking issues such as analysis of the key issues of the problems, formulating goals, and searching for strategies, the students overall did not distinguish the difference between similar and multidisciplinary grouping (Fig. 14), neither did the students of various genders (Fig. 15). However, the engineering, sociological, and psychological students regarded multidisciplinary was negative for problem analysis and method formulating for goal achieving (Fig. 16).

Finally, on the issue of inspiring personal creativity, students overall again did not distinguish the difference between the two types of grouping (Fig. 14); neither did students of different genders (Fig. 15). The explicit recognition of the positive influence appeared in the finance and management students, who regarded multidisciplinary as helpful for fostering creativity (Fig. 16).

There were also some findings about the effectiveness of the prepared toolkits as the primary working methods. Based on the close participatory observation of the entire workshop, some groups (like Group 2 in the similar disciplinary grouping and Group II in the multidisciplinary grouping) adopting the Collaborative Situation Construction, one of the six prepared toolkits, when trying to shape their consensus. Group V also returned to look for the six CD toolkits, and evaluated the feasibility of finding the way out from their predicament, when encountering an obstacle in their 
discussion progress. These two cases show the toolkits are also a reliable instrument for multidisciplinary collaboration.

\section{Producing the CD Methods}

At the last stage each multidisciplinary group was instructed to propose one or two CD method-modules (prototypes) (Table V), based on one action plan for community regeneration. Except Group V that was not able to fully understand the mission and objectives, all the other groups could propose their prototype modules to meet the tasks and deal with the problem they identified. The modules were designed for empathizing diverse individuals, removing the block of the communication, or fostering the formation of the consensus. What is more, each group's proposal would link to the basic collaborative methods (the six toolkits) produced by the research team, and at the same time was modified accordingly to the demand of the action plan. We regarded students' learning from the six toolkits and obtaining the fundamental concepts and idea as the process of convergent thinking, while the development of a new one as their own with the consideration of the real problems from the actual community was the process of divergent thinking.

TABLE V: PROTOTYPES FOR INTRA-CD

\begin{tabular}{|c|c|c|c|}
\hline Group & $\begin{array}{l}\text { Intra-CD } \\
\text { Modules } \\
\text { Proposal }\end{array}$ & Description & $\begin{array}{l}\text { Derived from } \\
\text { Demonstrated } \\
\text { PD/CD Methods? }\end{array}$ \\
\hline I & $\begin{array}{l}\text { Current } \\
\text { Situation } \\
\text { Survey }\end{array}$ & $\begin{array}{l}\text { Proposing the acceptable } \\
\text { bottom line of each } \\
\text { member, and trying to } \\
\text { assimilate each other's } \\
\text { objectives into one's } \\
\text { situation of life. }\end{array}$ & $\begin{array}{l}\text { - } \text { Consensus } \\
\text { First } \\
\text { - Empathy } \\
\text { Game }\end{array}$ \\
\hline II & $\begin{array}{l}\text { "The Snow } \\
\text { White" Method }\end{array}$ & $\begin{array}{l}\text { Amplifying } \\
\text { characteristics of each } \\
\text { member, and introducing } \\
\text { conflicts intentionally to } \\
\text { observe each member's } \\
\text { reaction to the possible } \\
\text { crisis. }\end{array}$ & $\begin{array}{l}\text { - Empathy } \\
\text { Game }\end{array}$ \\
\hline III & Multi-Ideals & $\begin{array}{l}\text { Proposing ideas from } \\
\text { members, and acquiring } \\
\text { professional's feedback } \\
\text { and suggestion according } \\
\text { to ideas' contexts. }\end{array}$ & - Open Space \\
\hline III & $\begin{array}{l}\text { "The Bumper } \\
\text { Cars" Method }\end{array}$ & $\begin{array}{l}\text { A "Collision" between } \\
\text { "top-down" (from ideal } \\
\text { to pragmatic situations) } \\
\text { and "bottom-up" (from } \\
\text { pragmatic to ideal } \\
\text { situation), to encourage } \\
\text { opinions' interweaving. }\end{array}$ & $\begin{array}{l}\text { - } \text { Bootlegging } \\
\text { - Collaborative } \\
\text { Situation } \\
\text { Construction }\end{array}$ \\
\hline IV & $\begin{array}{l}\text { "The Color } \\
\text { Palette" } \\
\text { Method }\end{array}$ & $\begin{array}{l}\text { Group members set up a } \\
\text { common aim, pose } \\
\text { opinions, give } \\
\text { evaluation, and converge } \\
\text { to the final consensus. }\end{array}$ & $\begin{array}{l}\text { - Open Space } \\
\text { - Collaborative } \\
\text { Situation } \\
\text { Construction }\end{array}$ \\
\hline IV & $\begin{array}{l}\text { Treasure } \\
\text { Solitaire }\end{array}$ & $\begin{array}{l}\text { Group members set up a } \\
\text { common topic and } \\
\text { propose an idea or } \\
\text { vision, followed by } \\
\text { another member one } \\
\text { after, to embody and } \\
\text { modify the result by } \\
\text { addressing the problems } \\
\text { and discussion. }\end{array}$ & $\begin{array}{l}\text { - Exquisite } \\
\text { Corpse }\end{array}$ \\
\hline
\end{tabular}

\section{E. Summary}

One of the aims of the research is to develop working method-modules for multidisciplinary collaboration and $\mathrm{PD} /$ cooperative design. The fostering of multidisciplinary collaboration, therefore, is the significant indicator. Due to the constraint in student recruitment and number, freshmen and sophomores comprised more than sixty percent of the participants. They have not really obtained the sufficient "professional" knowledge, neither the explicit characteristics shaped by skills, technique, and value. However, based on the exploration of the questions about similar or multidisciplinary grouping form their anonymous questionnaires and qualitative interviews, nearly 85 percent of students identified the problem of communication caused by multidisciplinary grouping, including its various ways of thinking. On the other hand, if viewing the analytical results showing the different preferences of grouping and working method-modules selection, students of each discipline still reveals a certain degree of commonality.

Students' feedbacks on co-design modules (the six toolkits) can preliminarily support the applicability of the self-learning toolkits for multidisciplinary collaboration in real educational situations and possibly initiating creativity. From students' final prototypes of collaborative method-modules, we can see the potential of fostering creativity that $\mathrm{CD} / \mathrm{PD}$ methods can offer. Also by well arranging the convergent and divergent thinking practices, we may design the course or the process for initiating creativity-even only its sparkles-for multidisciplinary collaboration.

There is another finding from this workshop. No solid correlation between the multidisciplinary grouping and the promotion of students' divergent thinking, such as multiperspectives, disclosing the unseen problems, and deepening discussion as we expected. A possible reason is that the duration of a two-day workshop is too short and not sufficient for practices, understanding the site of action planning, and producing multidisciplinary working method-modules. The limit of time became stressful and forced the students to be apt to rely on convergent thinking and emphasize on speed, accuracy, and logic, in order to form a single "best" answer to a clearly defined problem. For setting next experimental workshop or course to verify the assumption, the research team will adopt experiences and findings from this workshop as the improvement, such as creating a proper condition for divergent thinking.

\section{CONCLUSION}

The research utilized and combined convergent and divergent thinking into a workshop to develop a problem-based learning condition for multidisciplinary collaboration learning. For acquiring students with fundamental knowledge and skills that could develop their own collaborative method-modules, which could also be used as prototypes for developing mature co-design method-modules, the research team firstly developed six self-learning toolkits and let students practice the basic methods of co-design. Through two stages of practice, the practice of self-learning toolkits and that of producing 
collaborative method-modules for their own tasks, linked with convergent and divergent thinking, the workshop expected students could understand the problems from different perspectives and shape discussion based on different disciplinary backgrounds. As making a medium for producing final modules, each group was also instructed to propose an action plan in each stage, on which the suitable one or two collaborative method-modules could base and meet the action plans' tasks. From the process of the workshop and the outcomes of the toolkit practices and module proposals, we may preliminarily recognize the developed toolkits can work as $\mathrm{CD}$ modules and help students to gradually learn the methods of PD or co-design, and apply to deal with the real problems.

The research team also found from the workshop that the participating students preferred the grouping of same discipline while in the process of dealing with the real problems, although they had regarded themselves in favor of multidisciplinary grouping at the beginning. So as the tendency of using logical and systematic thinking to promptly achieve consensus and the final product, due to the difficulty of communication with peers of diverse backgrounds within stressfully limited time. Thus, in fact, they relied on convergent thinking more than divergent one, which caused their products not to be novel enough. The experience can be a base of the design and modification of future workshops and experiments, in which divergent thinking can have enough room to be developed properly and achieve better multidisciplinary collaboration with creativity. Finally, this workshop also found that gender and disciplinary factors might correlate to students' preferences of adopting convergent or divergent thinking. These findings are worthy for further studies.

Can abstract objective be designed? It is a question derived from the workshop and the final mission to design a multidisciplinary group's collaborative method-module, which caused a great deal of confusion among the students. The instructors and the teaching assistants had to explain many times to clarify the tasks the students were expected to do. A few possible reasons were proposed that perhaps could be hypotheses for further experiments. First, from the general knowledge, the "design" objective "should be" something physical and usually an object. A method for group collaboration could hardly be recognized as a design product; or, it was too abstract to be a design. Second, comparing to the conventional designs that face the (other) users, this self-facing one was somehow beyond their experiences.

\section{ACKNOWLEDGMENT}

We would like to thank Ministry of Science and Technology of Taiwan who sponsors the project (MOST 105-2511-S-002-016-MY3), also the D-School@NTU for applying for this course, teaching assistants from National Taiwan University, Tamkang University and National Dong Hwa University for assisting this workshop, and our students for their enthusiasm. Shih-Yao Lai and Liang-Gui Yu contributed equally to this paper and share the first authorship.

\section{REFERENCES}

[1] R. J. Sternberg and T. I. Lubart, Defying the Crowd: Simple Solutions to the Most Common Relationship Problems, NY: Free Press, 1995

[2] J. W. Prados, "Engineering education in the united states: past, present, and future," presented at the 1998 International Conference on Engineering Education, Rio de Janeiro, Brazil, Aug. 17-20, 1998.

[3] Rugarcia, R. M. Felder, D. R. Woods, and J. E. Stice, "The future of engineering education I. a vision for a new century," Chem. Engr. Education, vol. 34, no. 1, pp. 16-25, Dec. 2000.

[4] N. P. Kirillov, E. G. Leontyeva, and Y. A. Moiseenko, "Creativity in engineering education," presented at the 2014 International Conference on Research Paradigms Transformation in Social Science, Tomsk, Russian Federation, Oct. 16-18, 2014

[5] N. P. Kirillov, E. G. Leontyeva, and Y. A. Moiseenko, "Creativity in engineering education," Procedia - Social and Behavioral Sciences, vol. 166 , pp. 360-363, Jan. 2015.

[6] D. H. Cropley and A. J. Cropley, The Psychology of Innovation in Organizations, 1st ed. NY: Cambridge University Press, 2015.

[7] J. P. Guilford, "Creativity," American Psychologist, vol. 5, no. 9, pp 444-454, Sep. 1950.

[8] J. P. Guilford, The Nature of Human Intelligence, 1st ed. NY: McGraw-Hill, 1967.

[9] A. B. VanGundy and L. Naiman, Orchestrating Collaboration at Work, 1st ed. NJ: Wiley, 2003.

[10] T. Bratteteig and I. Wagner, "Spaces for participatory creativity," in Proc. the 11th Biennial Participatory Design Conference, pp. 51-60, 2010.

[11] K. M. Hecht and S. Maass, "Teaching participatory design," in Proc. the Tenth Anniversary Conference on Participatory Design, pp 166-169, 2008.

[12] H. Gardner, Frames of Mind: The Theory of Multiple Intelligences, 1st ed. Michigan, NY: Basic Books, 1983.

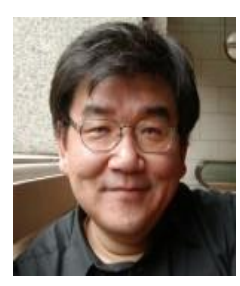

Shih-Yao Lai was born in Taipei, Taiwan, in 1963 He obtained his first degree of bachelor in architecture from the Dept. of Architecture, Tunghai University, Taichung Taiwan (1988), the master of science in building and planning from Graduate Institute of Building and Planning, National Taiwan University (NTU), Taipei Taiwan (1993), the master of science in architectural history and theory from Bartlett School of Graduate Studies, University College London, United Kingdom (2001), and the doctor of philosophy in architecture and urbanism from Bartlett School of Architecture, University College London, United Kingdom (2010).

He is now an assistant professor of Graduate Institute of Building and Planning, NTU, Taipei Taiwan. Other working experience includes Assistant Professor of the Department of Tourism, Shi Hsin University, Director of Architectural Design of Formosa Green Consultants (Urban Planning and Development), Associate Architect of W.Y. Sun \& Associates, Architect \& Engineers, Landscape Architect and Planner of Dillingham Associates, and Senior Planner of Building \& Planning Research Foundation, NTU.

Dr. Lai also an active member of Community Empowering Society (Taiwan), Architectural Institute of Taiwan, Architecture Reform Society (Taiwan), Society of Architectural Historians of Taiwan, Taiwan Alliance for Architectural Modernity, and the Organization of Urban Re-s.

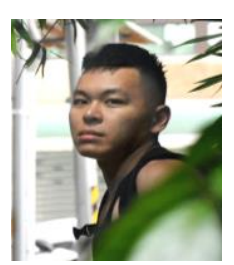

Liang-Gui Yu was born in Penghu on 29 June 1988. He obtained his first two degrees of bachelor of science in chemistry and life science from the Dept. of Chemistry and the Dept. of Life Science, National Tsinghua University, Hsinchu Taiwan (2011), the master of science in biochemical science and technology from the Dept. of Biochemical Science and Technology, NTU, Taipei Taiwan (2015), and he is now studying for degree of the doctor of philosophy in urban design and critical heritage studies from Graduate Institute of Building and Planning, NTU, Taipei Taiwan.

$\mathrm{He}$ is now a research assistant in Graduate Institute of Building and Planning, NTU, Taipei Taiwan. His current research interests are city image, historical urban landscape, urban settlement and informal landscape, and critical heritage studies. 


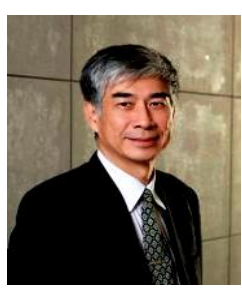

Shang-Hsien (Patrick) Hsieh was born in Taipei, Taiwan in 1963. He received his bachelor of science in civil engineering in 1985 from NTU, and his master of science and doctor of philosophy in civil and environmental engineering from Cornell University, U.S.A. in 1990 and 1993, respectively.

$\mathrm{He}$ is a professor in the Computer-Aided Engineering Division of Department of Civil Engineering at NTU, Taipei, Taiwan. He is currently serving as Chairman of Department of Civil Engineering in NTU and Director of the Research Center for Building \& Infrastructure Information Modeling and Management in the Department. From 1993 to 1995, he worked as a Postdoctoral Research Associate in the School of Civil Engineering at Purdue University, U.S.A. He joined the Department of Civil Engineering at NTU in 1995 and had since served as the Chief of Extracurricular Activities Section in Office of Student Affairs, Vice-Chairman of Department of Civil Engineering, and Deputy Dean for Office of International Affairs. He has a wide range of research interests, including engineering \& construction simulations, engineering information \& knowledge management systems, innovative engineering education, parallel and distributed engineering computing, earthquake engineering and structural dynamics, and object-oriented software development.

Prof. Hsieh is a member of Board of Directors of the International Society for Computing in Civil and Building Engineering since 1999 and served as the society's President from 2006 to 2008. He is also active members of several academic societies, including American Society of Civil Engineers, American Society of Engineering Education, The Chinese Institute of Engineers, Chinese Institute of Civil and Hydraulic Engineering, Chinese Society of Structural Engineering, Chinese Taiwan Society for Earthquake Engineering, and The Institute of Engineering Education Taiwan.

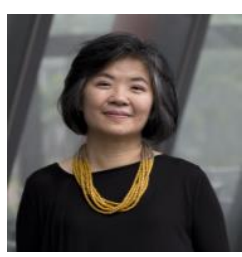

Mei-Mei Song was born in Taipei, Taiwan in 1966 She received her bachelor of art in education in 1989 from National Chengchi University, Taiwan, and her master of art in educational administration and doctor of education in organization and leadership from Teachers College, Columbia University, U.S.A. in 1991 and 2001, respectively.

She is an associate professor in the Graduate Institute of Futures Studies at Tamkang University (TKU), Taiwan as well as the Founder and Director of the Center for Futures Intelligence and Research (C-FAR) at the same institution. She worked as an assistant researcher in the Center for Higher Education Research and assistant professor in the
Department of Multiculture and Language at TKU. She has a wide range of research interests, which include futures thinking, educational change, globalization, and cross-disciplinary culture. Her research interests in recent years focus on the integration of futures and design thinking - particularly in engineering education.

Prof. Song is a Fellow and Executive Board member of World Futures Studies Federation (WFSF). She is also a member of Association of Professional Futurists (APF). She served as Managing Editor of the Journal of Futures Studies from 2007 to 2010 and was the recipient of Jan Lee Martin Scholarship for Young Futurists in 2012. In 2017, Prof. Song exhibited two pieces of artwork at the Temporary Institute of Futures Studies exhibit at the Museum of Contemporary Art Antwerp (M HKA) in Belgium.

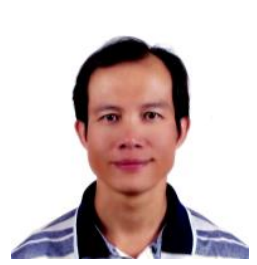

Te-Sheng (Teddy) Chang was born in Yilan, Taiwan in 1961. He received his bachelor of art in Chinese literature in 1988 from National Taiwan Normal University, and his master of science and doctor of philosophy in education from University of North Texas, U.S.A. in 1991 and 1996, respectively.

$\mathrm{He}$ is a professor at the Department of Educational and Human Potentials Development at National Dong-Hwa University (NDHU), Hualien, Taiwan. He is currently serving as director of Center for Teaching Excellence in NDHU. From 2012 to 2015, he worked as a dean of Hua-Shih College of Education in NDHU. He has been a visiting scholar among different institutes, including Department of Education, Kasetsart University, Thailand (June 2018-Sep 2018), Department of Psychology, New York University (August 2015-January 2016), College of Education, Yun-Nan Normal University, Ku-Ming, China (March, 2011), Institute of Sociology, Academia Sinica, Taiwan (August 2010-January, 2011), and Department of Psychology, University of Michigan, U.S.A (August 2007-January 2008). He has a wide range of research interests, including teaching and learning innovation, educational psychology, assessment and evaluation, teacher professional development, multicultural education, gender studies, and LGBT studies.

Prof. Chang is a current member of Board of the Taiwanese Feminist Scholars Association. He is also active members of several academic societies, including International Association for the Study of Sexuality, Culture and Society (IASSCS), International Congress of Psychology (ICP), American Psychology Association (APA), American Educational Research Association (AERA), European Society for Engineering Education (SEFI), and Chinese Association of Teacher Education, Taiwan. 